Article

\title{
Synthesis, Properties and Antimicrobial Activity of 5-Trifluoromethyl-2-formylphenylboronic Acid
}

\author{
Agnieszka Adamczyk-Woźniak 1,*iD, Jan T. Gozdalik ${ }^{1}$, Dorota Wieczorek ${ }^{2}$, \\ Izabela D. Madura ${ }^{1}$ (D), Ewa Kaczorowska ${ }^{1}$, Ewa Brzezińska ${ }^{1}$, Andrzej Sporzyński ${ }^{1}$ (D) \\ and Jacek Lipok ${ }^{2}$ \\ 1 Faculty of Chemistry, Warsaw University of Technology, ul. Noakowskiego 3, 00-664 Warsaw, Poland; \\ jgozdalik@ch.pw.edu.pl (J.T.G.); izabela@ch.pw.edu.pl (I.D.M.); ewak@ch.pw.edu.pl (E.K.); \\ ewabbrzezinska@gmail.com (E.B.); spor@ch.pw.edu.pl (A.S.) \\ 2 Faculty of Chemistry, University of Opole, ul. Oleska 48, 45-042 Opole, Poland; \\ dorwieczorek@uni.opole.pl (D.W.); jacek.lipok@uni.opole.pl (J.L.) \\ * Correspondence: agnieszka@ch.pw.edu.pl; Tel.: +48 222345737
}

Received: 3 December 2019; Accepted: 6 February 2020; Published: 12 February 2020

\begin{abstract}
Formylphenylboronic acids display many interesting features, not only from synthetic but also from an application as well as structural points of view. 5-Trifluoromethyl-2-formyl phenylboronic acid has been synthesized and characterized in terms of its structure and properties. The presence of an electron-withdrawing substituent results in a considerable rise in the acidity in comparison with its analogues. In some solutions, the title compound isomerizes with formation of the corresponding 3-hydroxybenzoxaborole. Taking into account the probable mechanism of antifungal action of benzoxaboroles, which blocks the cytoplasmic leucyl-tRNA synthetase (LeuRS) of the microorganism, docking studies with the active site of the enzymes have been carried out. It showed possible binding of the cyclic isomer into the binding pocket of Candida albicans LeuRS, similar to that of the recently approved benzoxaborole antifungal drug (AN2690, Tavaborole, Kerydin). In case of Escherichia coli LeuRS, the opened isomer displays a much higher inhibition constant in comparison with the cyclic one. The antimicrobial activity of the title compound was also investigated in vitro, showing moderate action against Candida albicans. The compound reveals higher activity against Aspergillus niger as well as bacteria such as Escherichia coli and Bacillus cereus. In case of Bacillus cereus, the determined Minimum Inhibitory Concentration (MIC) value is lower than that of AN2690 (Tavaborole). The results confirm potential of 2-formylphenylboronic acids as antibacterial agents and give a hint of their possible mechanism of action.
\end{abstract}

Keywords: acidity; antimicrobial; benzoxaborole; crystal; docking; equilibrium; formyl; Kerydin; phenylboronic; Tavaborole; trifluoromethyl

\section{Introduction}

Boronic acids and especially arylboronic acids are of significant importance in chemistry. There are many examples of application of arylboronic acids, among others: building blocks in organic chemistry, sensors and receptors, polymers, active ingredients of drugs, functionalization of nanoparticles, boron neutron capture therapy (BNCT) and positron emission tomography (PET) [1-5]. Formyl-substituted phenylboronic acids additionally display high synthetic utility due to presence of a reactive aldehyde group. Reduction of the 2-formyl isomers is a highly versatile and straightforward method for benzoxaboroles' synthesis [6]. The 2-formylphenylboronic acids are also very interesting from the structural point of view, since many interactions of the formyl group with the neighboring boronic unit are possible. Those interactions have been investigated by X-ray in the solid state [7]. One of 
the interesting phenomena of 2-formylphenylboronic acids is their possible isomerization in solution with the formation of cyclic isomers, which can be considered as 3-hydroxybenzoxaboroles [8]. As it was recently discovered, some 2-formylphenylboronic acids display antimicrobial activity, which was found to correlate with the amount of a cyclic isomer formed in DMSO (dimethylsulfoxide) solution [9]. At the same time, the presence of a fluorine substituent in arylboronic acids as well as in benzoxaboroles is crucial in their medicinal [10] and sensing applications. It enhances their acidity, resulting in binding the cis-diol bioanalytes at physiological conditions [11,12]. Fluorinated organic compounds show significantly different properties than analogous non-fluorinated ones. The former display higher lipophilicity and are able to form hydrogen bonds via the fluorine atom [13]. It is noteworthy that about $25 \%$ of known drugs contain the fluorine atom [14]. The recently approved benzoxaborole antifungal drug (AN2690, Scheme 1) also contains fluorine atom. The AN2690 structure was the first representative of a novel benzoxaborole-based group of biologically active compounds with a unique mechanism of action based on blocking the LeuRS (Leucyl t-RNA synthetase) of microorganisms [6]. The molecular basis of AN2690 action as antifungal agent is formation of its spiroboronate with AMP (adenosine monophosphate, AN2690-AMP, Scheme 1).<smiles>C#CC=Cc1ccc(C(F)(F)F)cc1B(O)O</smiles>

1<smiles>OB1OC(O)c2ccc(C(F)(F)F)cc21</smiles>

1a

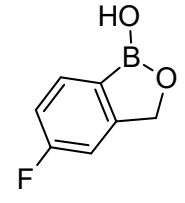

AN2690

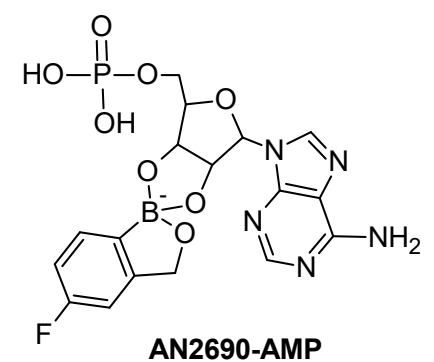

AN2690-AMP

Scheme 1. Structure of the 5-trifluoromethyl-2-formylphenylboronic acid (1), its cyclic isomer (1a), AN2690 and the AN2690-AMP spiroboronate.

The subject of the present work is the synthesis, structural study and spectral characterization as well as evaluation of the acidity and antimicrobial activity of 5-trifluoromethyl-2-formyl- phenylboronic acid (1, Scheme 1). The title compound is commercially available (CAS 1204580-94-8) and has been previously used synthetically [15], however not characterized either spectroscopically or in terms of its physicochemical properties. Compound $\mathbf{1}$ is able to tautomerize with formation of a cyclic isomer (1a), which resembles the structure of AN2690 (Scheme 1) - the active ingredient of the antifungal drug Kerydin. Nothing is known however about the actual amount of 1a in solution or antimicrobial activity of the title compound. All those issues are the subject of the current paper. Studies of isomers of 1, including analog of AN2690, are in progress and will be reported in future.

\section{Results and Discussion}

\subsection{Synthesis, Molecular and Crystal Structure}

The title compound was synthesized from the corresponding bromobenzaldehyde in a two-step reaction according to a typical procedure [10] (Scheme 2). The purity and homogeneity of the sample was confirmed by elemental analysis.<smiles>O=Cc1ccc(C(F)(F)F)cc1Br</smiles><smiles>COC(OC)c1ccc(C(F)(F)F)cc1Br</smiles>

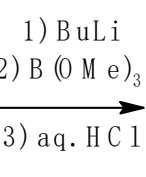

Scheme 2. The synthesis of the 5-trifluoromethyl-2-formylphenylboronic acid (1). 
Molecules of $\mathbf{1}$ crystallize in the centrosymmetric space group of the triclinic system. Two crystallographically independent molecules (1-I and 1-II) are present in an asymmetric part of the unit cell, forming a hydrogen bonded motif described at the second level of the Etter's graph [16] as $R_{2}^{2}(8)$, thus resembling the most popular synthon observed for boronic acids with the syn-anti conformation of the $\mathrm{B}(\mathrm{OH})_{2}$ moiety (Figure 1a). In the case of $\mathbf{1}$, such a conformation is in a way forced by the presence of an intramolecular $\mathrm{O}-\mathrm{H}$... O hydrogen bond with the formyl group present at ortho position. The geometry of all H-bonds observed in $\mathbf{1}$ are collected in Table 1 whereas other geometrical parameters, showing the likeness of both molecules (1-I and 1-II), can be found in Table S1 and Table S2 in the Supplementary Materials. Both symmetrically independent molecules are essentially flat, excluding F atoms, with root-mean-square deviation from planarity (RMSD) of 0.025(1) and 0.077(1) $\AA$ for 1-I and 1-II, respectively. A close inspection with the aid of the Hirshfeld surface (HS) analysis [17] of intermolecular interactions between the basic structural motives revealed that stacking interactions are predominant in building a crystal (see corresponding red and blue areas on HS surface in Figure 1b). The shortest distances between planes containing the motif and related by the inversion and translation are 3.283(1) and 3.442(1) A. Moreover, very weak C-H...O hydrogen bonds between hydrogen atom of the formyl group and O1/O11 atom are also present, joining the motives into flat tapes running almost parallel to the (0-11) crystallographic plane. Taking into account the mentioned interactions a layer perpendicular to [001] direction and terminated with disordered $\mathrm{CF}_{3}$ groups is observed (Figure 1c). It is worth mentioning that two other structurally characterized ortho formyl substituted boronic acids, namely 2-formylphenyl- [7] and 2-formyl-3-fluorophenylboronic acid [8] are also flat and forming the $R_{2}^{2}(8)$ basic structural motif as well as stacking columns.

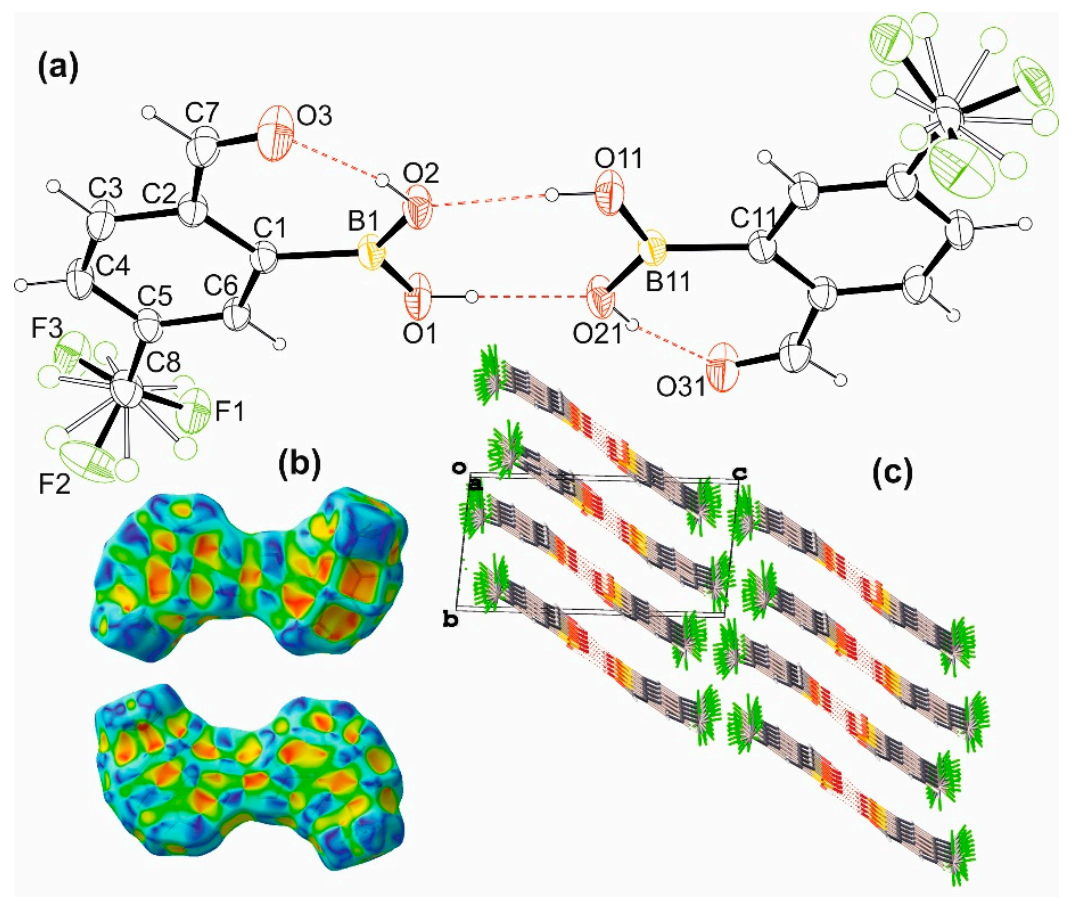

Figure 1. (a) Hydrogen bonded basic structural motif formed by two independent molecules 1-I and 1-II. Ellipsoids are given with 30\% probability; (b) Molecular Hirshfeld surface (HS) with mapped surface index for the motif. Both sides of the HS surface are shown; (c) Packing diagram of $\mathbf{1}$. 
Table 1. Geometry of hydrogen bonds in $\mathbf{1}$.

\begin{tabular}{|c|c|c|c|}
\hline & $\mathbf{H} \cdots \mathbf{A}$ & $\mathrm{D} \cdots \mathrm{A}$ & D-H $\cdots A$ \\
\hline \multicolumn{4}{|l|}{ Intramolecular } \\
\hline $\mathrm{O} 2-\mathrm{H} 2 \ldots \mathrm{O} 3$ & $1.82(1)$ & $2.619(1)$ & $164(2)$ \\
\hline O21-H21 .. O31 & $1.81(1)$ & $2.605(1)$ & $164(2)$ \\
\hline \multicolumn{4}{|l|}{ Intermolecular } \\
\hline O1-H1 . . O21 & $1.95(1)$ & $2.774(1)$ & 177(2) \\
\hline O11-H11 ... O2 & 1.97(1) & $2.779(1)$ & 174(2) \\
\hline C7-H7 .. O $1^{\mathrm{i}}$ & 2.61 & $3.254(2)$ & 127 \\
\hline $\mathrm{C} 71-\mathrm{H} 71 \ldots \mathrm{O} 11$ ii & 2.56 & $3.220(2)$ & 128 \\
\hline
\end{tabular}

Symmetry operations: (i) $-1+x, y, z$; (ii) $1+x, y, z$.

\subsection{Acidity Constant Determination}

The 5-trifluoromethyl-2-formylphenylboronic acid (1) similarly to other boronic acids is Lewis acid and exists in the acid-base equilibrium (Scheme 3). In alkaline conditions, boronic group assumes tetragonal form instead of a trigonal, flat form [18-20]. This causes change in UV spectrum which is shown in Figure 2. The $\mathrm{p} K_{\mathrm{a}}$ of arylboronic acids is influenced by electronic as well as steric effects of the substituents. Introduction of the formyl group into position " 2 " of the boronic acids causes significant increase of acidity (drop in $\mathrm{p} K_{\mathrm{a}}$ ). In case of aryl compounds with a fluorine substituent, both mesomeric and inductive effects take place, while the trifluoromethyl group displays only strong inductive effect [21]. The acidity of boronic trifluoromethyl derivatives is generally higher than that of analogous fluorine substituted molecules. It should be however noted that it also strongly depends on the position of the substituents (see Table 2 for values) [10,22-24].<smiles>O=Cc1ccc(C(F)(F)F)cc1B(O)O</smiles>

Scheme 3. Acid-base equilibrium in 5-trifluoromethyl-2-formylphenylboronic acid (1).

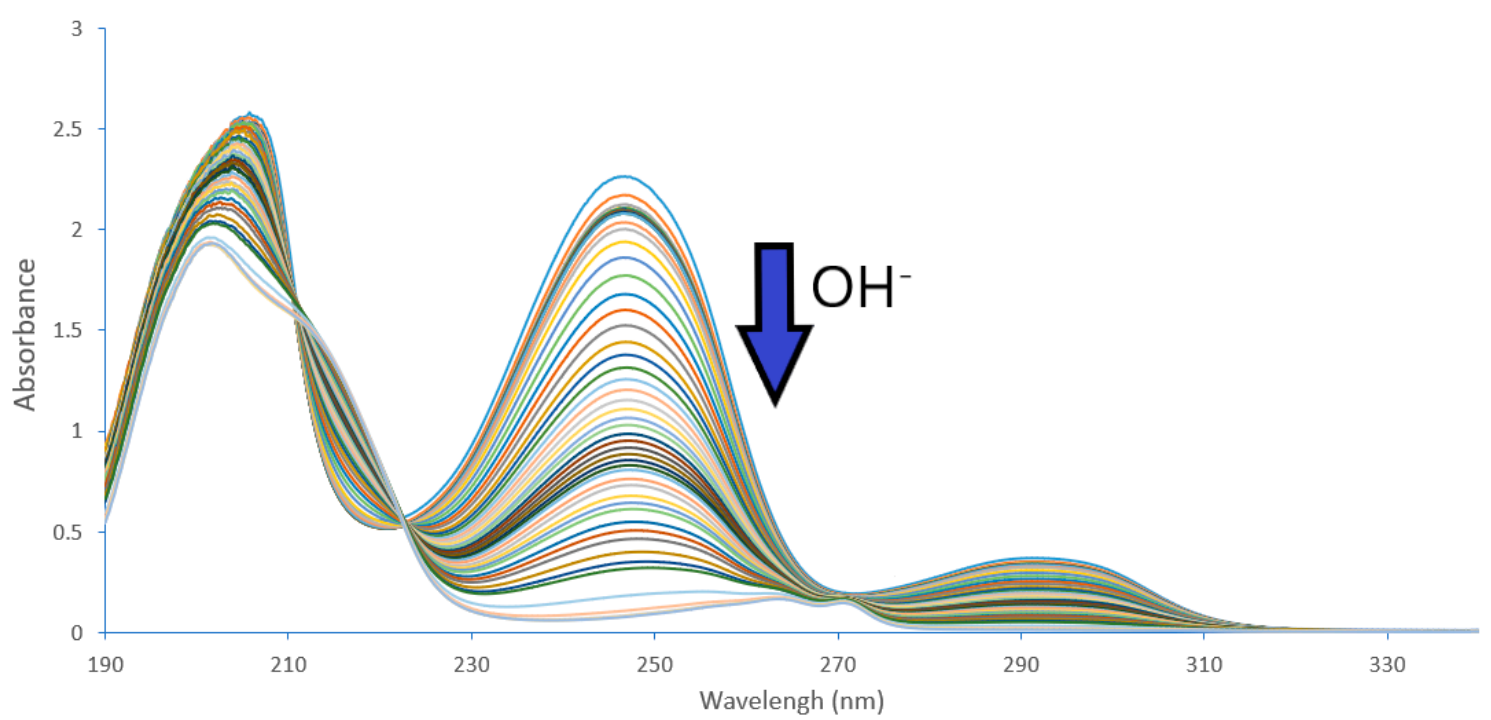

Figure 2. Observed change in spectrum during titration of compound 1 with sodium hydroxide. 
Table 2. Selected boronic acids and their $\mathrm{p} K_{\mathrm{a}}$ values.

\begin{tabular}{|c|c|c|c|}
\hline General Formula & Substituent & $\mathrm{p} K_{\mathrm{a}}$ Value & Reference \\
\hline \multirow{2}{*}{$\mathrm{HO}_{-\mathrm{B}}, \mathrm{OH}$} & - & 8.86 & [10] \\
\hline & $3-\mathrm{F}$ & $7.50 \pm 0.02$ & [22] \\
\hline \multirow{4}{*}{5} & $3-\mathrm{CF}_{3}$ & $7.85 \pm 0.05$ & [23] \\
\hline & $2-\mathrm{CHO}$ & 7.31 & [24] \\
\hline & $2-\mathrm{CHO}, 5-\mathrm{F}$ & $6.72 \pm 0.03$ & [10] \\
\hline & $2-\mathrm{CHO}, 5-\mathrm{CF}_{3}(\mathbf{1})$ & $5.67 \pm 0.01$ & This work \\
\hline
\end{tabular}

The acidity constant of $\mathbf{1}$ was determined according to the previously reported method $[25,26]$. The obtained value $(5.67 \pm 0.01)$ is the lowest among analogous 2 -formylphenylboronic acids and generally among other previously described substituted phenylboronic acids [3]. The determined value follows the general trend that replacing the $\mathrm{F}$ substituent with the $\mathrm{CF}_{3}$ substituent results in a drop of $\mathrm{p} K_{\mathrm{a}}$ by approximately 1 unit (see Table 2 for values). A relatively high acidity of $\mathbf{1}$ should enhance diols binding, possibly facilitating formation of a spiroboronate with adenosine monophosphate, which may result in antimicrobial activity.

\subsection{Spectral Characterization, Cyclization Equilibrium}

2-Formyl-substituted boronic acids may exist in solutions in tautomeric equilibrium-open and cyclic form, which was previously described [8-10,27]. Until today, some halogen-substituted boronic acids were investigated [8] as well as 2,6-diformylphenylboronic acid [27] and all isomers of mono-fluoro-substituted 2-formylphenylboronic acids $[9,10]$. The ${ }^{1} \mathrm{H}$ NMR (Nuclear Magnetic Resonance) spectra of compound $\mathbf{1}$ have been measured in several deuterated solvents (chloroform, benzene, DMSO, acetone and water) to investigate the influence of a solvent on possible tautomerization and formation of a cyclic isomer 1a (Scheme 4). It was found that only isomer $\mathbf{1}$ was present in benzene and chloroform solutions (Table 3). Interestingly the proton of a formyl group in $\mathbf{1}$ couples with the H3 proton in $\mathrm{CDCl}_{3}$ solution, which has been confirmed on the basis of the ${ }^{1} \mathrm{H}-{ }^{1} \mathrm{H}$ COSY spectrum.<smiles>O=Cc1ccc(C(F)(F)F)cc1B(O)O</smiles>

1<smiles>OB1OC(O)c2ccc(C(F)(F)F)cc21</smiles>

1 a

Scheme 4. Atom numbering in $\mathbf{1}$ and $\mathbf{1 a}$.

In contrast to chloroform and benzene solutions, certain amounts of 1a contained the acetone, DMSO and aqueous solutions. In case of the title compound solutions in DMSO an interesting phenomenon was observed. In the event of low concentration of the sample (ca. $0.002 \mathrm{M})$, a coupling between the hydrogen and hydroxyl group in position " 3 " of the oxaborole ring is manifested in the ${ }^{1} \mathrm{H}$ NMR spectrum. The corresponding correlation peak was present in the ${ }^{1} \mathrm{H}-{ }^{1} \mathrm{H}$ COSY spectrum of the sample as well. However, during raise in concentration a simultaneous broadening of the signal corresponding to hydroxyl group is observed and the neighboring proton signal becomes a singlet. This can be attributed to formation of dimeric species with increasing concentration of the sample. However, the correlation signal is still present in the ${ }^{1} \mathrm{H}-{ }^{1} \mathrm{H}$ COSY spectrum of the most concentrated sample studied ( $0.02 \mathrm{M}$, see Supplementary Materials for picture). The 1-1a equilibrium was investigated by ${ }^{1} \mathrm{H}$ NMR and ${ }^{19} \mathrm{~F}$ NMR spectroscopy at $25^{\circ} \mathrm{C}$. The ratio of isomers was determined by integration of characteristic and well isolated signals corresponding to each of the isomers (Table 4). Four solutions differing by concentration have been prepared in DMSO $(2.3 \mathrm{mg}, 11.1 \mathrm{mg}, 27.2 \mathrm{mg}$ and 
$29.7 \mathrm{mg}$ of 1 in $0.5 \mathrm{~mL}$ DMSO was dissolved) and four solutions in acetone (2.4 mg, $10.1 \mathrm{mg}, 21.1 \mathrm{and}$ $29.3 \mathrm{mg}$ of $\mathbf{1}$ in $0.5 \mathrm{~mL}$ acetone was dissolved). At studied concentrations: (0.002-0.027M), the ratio of 1 and 1a does not depend on the concentration of the sample. The values of cyclization constant $\left(K_{c y c l}\right)$ in acetone, DMSO and $\mathrm{D}_{2} \mathrm{O}$ solutions were calculated according to the following Equation (1):

$$
K_{c y c l}=\frac{I_{1 a}}{I_{1}}
$$

where $I_{1 a}$ stands for the integrate of the signal corresponding to 1a and $I_{1}$ stands for the integrate of the signal corresponding to 1 in the appropriate spectrum.

Table 3. ${ }^{1} \mathrm{H},{ }^{11} \mathrm{~B}$ and ${ }^{19} \mathrm{~F}$ NMR chemical shifts of the title compound in various solvents.

\begin{tabular}{|c|c|c|c|c|c|c|c|c|}
\hline \multirow{3}{*}{$\begin{array}{l}\text { Solvent } \\
\text { (Form) }\end{array}$} & \multicolumn{6}{|c|}{${ }^{1}$ H NMR } & \multirow[t]{3}{*}{${ }^{11} B$} & \multirow[t]{3}{*}{${ }^{19} \mathrm{~F}$} \\
\hline & \multirow{2}{*}{$\mathrm{B}(\mathrm{OH})_{2}$} & \multicolumn{2}{|c|}{$\mathrm{CHO}$} & \multirow{2}{*}{ H3 } & \multirow{2}{*}{ H4 } & \multirow{2}{*}{ H6 } & & \\
\hline & & $\mathrm{OH}$ & $\mathbf{H}$ & & & & & \\
\hline $\mathrm{CDCl}_{3}(\mathbf{1})$ & $7.13(\mathrm{~s})$ & \multicolumn{2}{|c|}{$10.04(\mathrm{~m})$} & $8.54(\mathrm{~m})$ & $7.97(\mathrm{~m})$ & $\begin{array}{c}8.06(\mathrm{~d}) \\
{ }^{3} J_{\mathrm{H} 5}=7.8\end{array}$ & $27(\mathrm{~s})$ & -63.44 \\
\hline $\mathrm{C}_{6} \mathrm{D}_{6}(\mathbf{1})$ & $7.04(\mathrm{~s})$ & \multicolumn{2}{|c|}{$9.04(\mathrm{~s})$} & $8.55(\mathrm{~m})$ & $7.20(\mathrm{~m})$ & $\begin{array}{c}6.73(\mathrm{~d}) \\
{ }^{3} J_{\mathrm{H} 5}=7.8\end{array}$ & $27(\mathrm{~s})$ & -63.29 \\
\hline $\begin{array}{c}\left(\mathrm{CD}_{3}\right)_{2} \mathrm{CO} \\
(\mathbf{1})\end{array}$ & $7.84(\mathrm{~s})$ & \multicolumn{2}{|c|}{$10.40(\mathrm{~s})$} & $8.10(\mathrm{~m})$ & $7.93(\mathrm{~m})$ & $8.15(\mathrm{~m})$ & $29(\mathrm{~s})$ & -62.94 \\
\hline $\begin{array}{c}\left(\mathrm{CD}_{3}\right)_{2} \mathrm{CO} \\
(\mathbf{1 a})\end{array}$ & $8.50(\mathrm{~s})$ & $\begin{array}{c}6.38(\mathrm{~d}) \\
{ }^{3} J_{\mathrm{H}}=7.9\end{array}$ & $\begin{array}{c}6.22(\mathrm{~d}) \\
{ }^{3} \mathrm{~J}_{\mathrm{OH}}=8.1\end{array}$ & $8.01(\mathrm{~m})$ & $7.85(\mathrm{~m})$ & $7.70(\mathrm{~m})$ & $31(\mathrm{~s})$ & -61.98 \\
\hline$\left(\mathrm{CD}_{3}\right)_{2} \mathrm{SO}(\mathbf{1})$ & $8.47(\mathrm{~s})$ & \multicolumn{2}{|c|}{$10.24(\mathrm{~s})$} & $7.89(\mathrm{~m})$ & $7.91(\mathrm{~m})$ & $8.07(\mathrm{~m})$ & $30(s)$ & -61.67 \\
\hline $\begin{array}{c}\left(\mathrm{CD}_{3}\right)_{2} \mathrm{SO} \\
(\mathbf{1 a})\end{array}$ & $9.57(\mathrm{~s})$ & $\begin{array}{c}7.23(\mathrm{~d}) \\
{ }^{3} J_{\mathrm{H}}=8.1\end{array}$ & $\begin{array}{c}6.25(\mathrm{~d}) \\
{ }^{3} \mathrm{~J}_{\mathrm{OH}}=8.1\end{array}$ & $8.01(\mathrm{~m})$ & $7.85(\mathrm{~m})$ & $7.64(\mathrm{~m})$ & $30(\mathrm{~s})$ & -60.73 \\
\hline
\end{tabular}

Table 4. Cyclization constant of title compound in various solvents (based on ${ }^{1} \mathrm{H}$ NMR).

\begin{tabular}{cccc}
\hline Solvent & $\begin{array}{c}\text { Cyclization } \\
\text { Constant }\end{array}$ & $\begin{array}{c}{ }^{\mathbf{1}} \mathbf{H} /{ }^{\mathbf{1 9}} \text { F NMR Shift of } \\
\text { the Cyclic Form (1a) }\end{array}$ & $\begin{array}{c}{ }^{\mathbf{1}} \mathbf{H} /{ }^{\mathbf{1 9}} \text { F NMR Shift of } \\
\text { The Opened Form (1) }\end{array}$ \\
\hline$\left(\mathrm{CD}_{3}\right)_{2} \mathrm{SO}$ & $0.59 \pm 0.01$ & $6.25 /-60.73$ & $10.24 /-61.67$ \\
$\left(\mathrm{CD}_{3}\right)_{2} \mathrm{CO}$ & $0.24 \pm 0.02$ & $6.22 /-61.98$ & $10.40 /-62.94$ \\
$\mathrm{D}_{2} \mathrm{O}$ & $0.26 \pm 0.03 *$ & $6.36 /-62.22$ & $10.06 /-63.26$ \\
\hline
\end{tabular}

* Due to very low solubility of $\mathbf{1}$ in $\mathrm{D}_{2} \mathrm{O}$ the spectrum is of a relatively low signal to noise ratio.

The ${ }^{13} \mathrm{C}$ NMR chemical shifts of the title compound in $\mathrm{CDCl}_{3}$ are given in Table 5. The observed chemical shifts and coupling constant with fluorine atoms of the $\mathrm{CF}_{3}$ group and $\mathrm{C} 5$ carbon are typical and coherent with literature values [23,28]. Other signals in ${ }^{13} \mathrm{C}$ were assigned on the basis of the ${ }^{1} \mathrm{H}_{-}{ }^{13} \mathrm{C}$ HSQC (Heteronuclear Single Quantum Correlation) spectrum. A comparison with the literature values of the analogous fluorinated compound, namely 5-fluoro-2-formylphenylboronic acid, helped in assigning signals of carbon C2 of both forms [10]. In the carbon spectrum, no signals corresponding to trifluoromethyl group or C5, and C1 carbons of isomer 1a were observed due to both specific shapes of the mentioned signals as well as low concentration of isomer 1a in the sample.

Table 5. ${ }^{13} \mathrm{C}$ NMR chemical shifts of the title compound $\left(75 \mathrm{MHz}, \mathrm{DMSO}-\mathrm{d}_{6}\right)$.

\begin{tabular}{ccccccccc}
\hline Form & CHO/CH-OH & $\mathbf{C F}_{3}$ & C1 & C2 & C3 & C4 & C5 & C6 \\
\hline $\mathbf{1}$ & $193.82(\mathrm{~s})$ & $\begin{array}{c}124.5(\mathrm{q}) \\
1 J_{\mathrm{F}}=270.5\end{array}$ & $140.8(\mathrm{bs})$ & $\begin{array}{c}142.1(\mathrm{~d}) \\
4 J_{\mathrm{F}}=1.1\end{array}$ & $129.5(\mathrm{~m})$ & $125.7(\mathrm{~m})$ & $\begin{array}{c}132.2(\mathrm{q}) \\
{ }^{2} J_{\mathrm{F}}=31.5\end{array}$ & $129.9(\mathrm{~s})$ \\
\hline $\mathbf{1 a}$ & $97.06(\mathrm{~s})$ & $\begin{array}{c}\text { Not } \\
\text { Observed }\end{array}$ & $\begin{array}{c}\text { Not } \\
\text { Observed }\end{array}$ & $158.9(\mathrm{~s})$ & $\begin{array}{c}126.8(\mathrm{q}) \\
{ }^{3} J_{\mathrm{F}}=3.7\end{array}$ & $127.8(\mathrm{~m})$ & $\begin{array}{c}\text { Not } \\
\text { Observed }\end{array}$ & $123.8(\mathrm{~s})$ \\
\hline
\end{tabular}

The abbreviations: s (singlet), b (broad), m (multiplet), q (quartet), J (coupling constant given in Hertzs (Hz)). 


\subsection{Docking Studies of Interactions of AN2690 and 1/1a with Candida albicans' and Eschericha coli LeuRS}

It is worth noting that a reasonable amount of the cyclic isomer 1a is present in DMSO solution, which is used in the in vitro studies of antimicrobial properties of $\mathbf{1}$ (Table 4). In case of the previously reported isomeric fluoro-2-formylphenylboronic acids, the antimicrobial activity seemed to correlate with the amount of the cyclic isomer in DMSO solution [9]. It was concluded from structural similarities of the cyclic isomers to benzoxaborole drug AN2690. The molecular mechanism of action of AN2690 has been established on the basis of structural studies of the crystal structure of the corresponding leucyl-RS synthetase-EC 6.1.1.4 [29,30]. It was found that AN2690 forms a spiroboronate with adenosine monophosphate (AMP) within the editing domain of the cytoplasmic LeuRS of C. albicans. It is worth noting that LeuRS is also a possible molecular target in other microorganisms [6]. In order to prepare models for docking studies, crystal structures of the proteins with bound AN2690 was taken from the Protein Databank and the ligand (the AN2690-AMP spiroboronate) has been removed from structures. To verify the docking procedure, the AN2690-AMP spiroboronate was docked into such an obtained protein resulting in structure analogous to the starting one (Figure 3a). With the docking procedure in hand, the binding the title compound $\mathbf{1}$ and its cyclic isomer 1a was investigated to compare their potential in enzyme interactions with that of the AN2690. Needless to say that 1a is a chiral molecule and each of the enantiomers can display different activity. Therefore, each of the enantiomers has been evaluated. In case of every input structure (see Supplementary Materials for structures) 300 docking procedures according to the genetic algorithm have been carried out. In case of all the possible spiroboronates, the starting position of the ligand was analogous to that of AN2690 known from the experimental complex [29]. The search for binding sites covered the whole protein structure. Optimal structures of all the ligands and corresponding spiroboronates are given in Supplementary Materials. Figure 3b shows the AN2690-AMP spiroborate (pink) as well as analogous 1a-AMP spiroboronate (green) docked into the Candida albicans LeuRS binding pocket. The position of all the spiroboronates (AN2690-AMP, 1-AMP and 1a-R-AMP-B) is similar (Figure 3c), which suggests that the mode of action of $\mathbf{1}$ against Candida albicans may be analogous to the known antifungal drug AN2690.

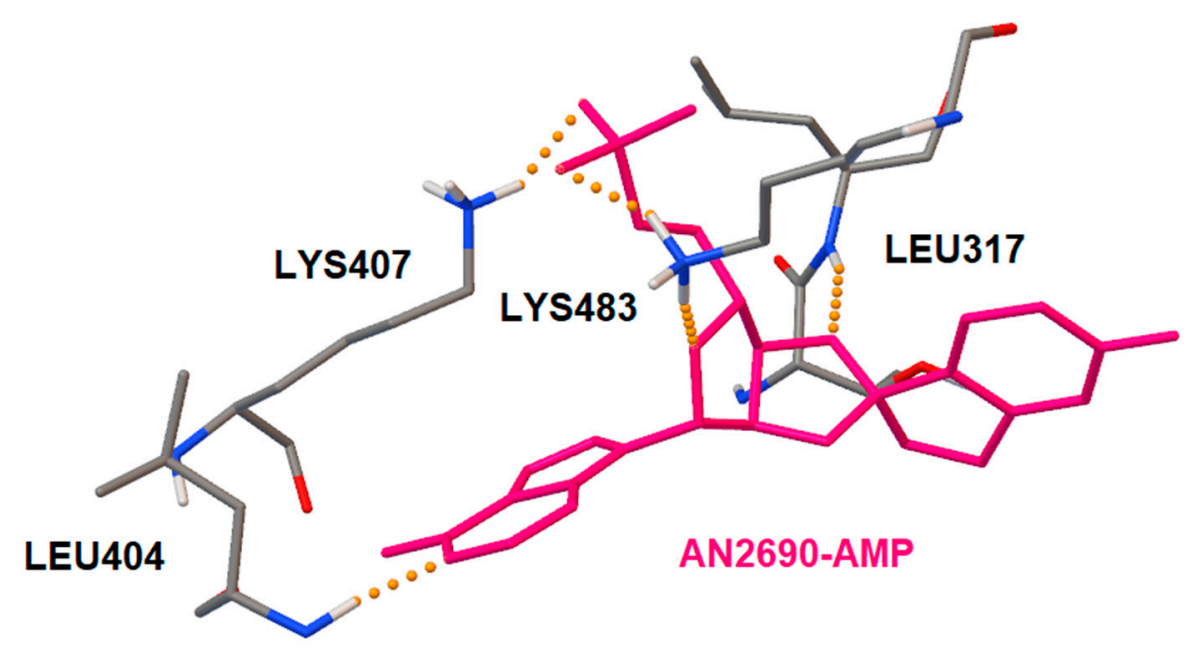

(A)

Figure 3. Cont. 


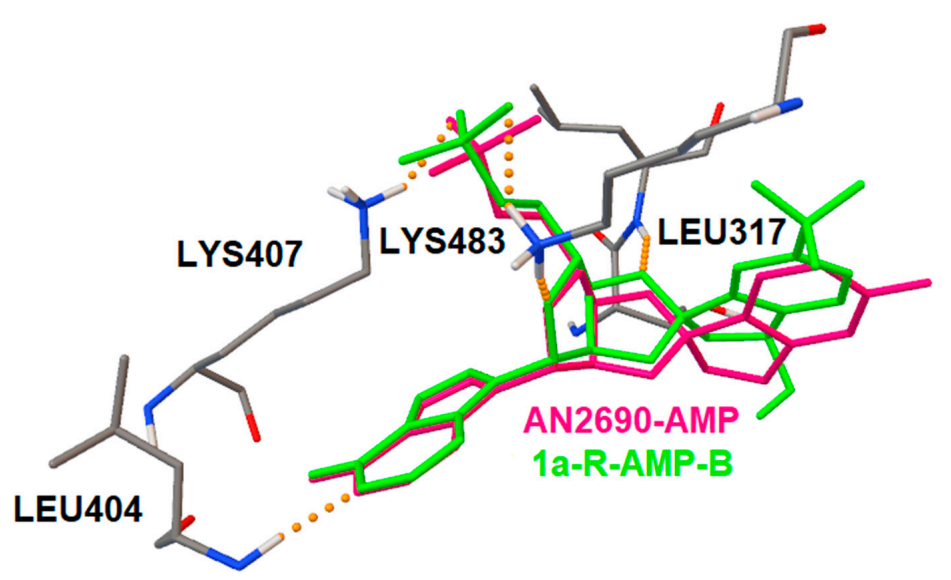

(B)

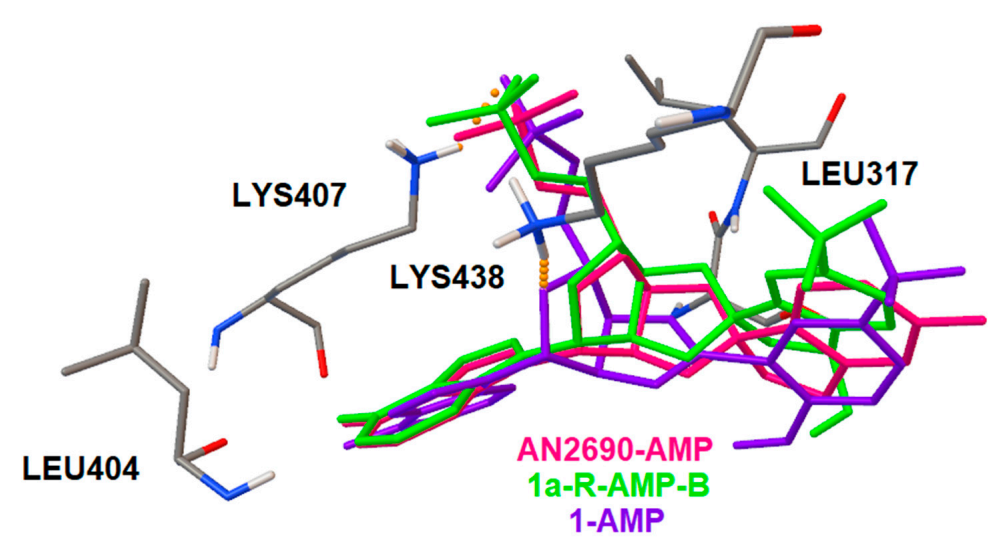

(C)

Figure 3. (A) The structure of AN2690-AMP spiroboronate docked into the Candida albicans LeuRS binding pocket (B) the AN2690-AMP spiroboronate (pink) along with 1a-AMP spiroboronate (green) (C) AN2690-AMP spiroboronate (pink) along with 1a-AMP spiroboronate (green) and 1-AMP spiroboronate (purple) docked into Candida albicans LeuRS. Dotted lines stand for hydrogen bonds.

To judge the binding of the investigated ligands, the binding energy was determined as a difference between the energy of a protein-ligand complex and the sum of the energy of ligand and a protein. Table 6 contains the lowest binding energy, number of structures in the best cluster along with mean binding energy and inhibition constants for the best cluster. The number of hydrogen bonds between ligand and the enzyme is also given. Supplementary Materials contain all the input and docked structures. The best binding energy of $(-11.89 \mathrm{kcal} / \mathrm{mol})$ displayed the AN2690-AMP spiroboronate forming five hydrogen bonds with the protein. The remaining ligands studied showed considerably higher energy of binding (weaker interaction). It is worth noting that the energies of binding along with the inhibition constants of 1a-AMP spiroboronates are better than that of the 1-AMP spiroboronate, which suggests that $\mathbf{1 a}$ is the most probably the active isomer. However, only ligand 1a-R-AMP-B forms as many hydrogen bonds as the parent drug ligand and displays similar inhibition constant (Table 6). It is worth to underline that due to chirality of molecule 1a and probable differences in activity of optical isomers, the actual activity may be lower than it could be expected from amount of the 1a in solution. The presented docking studies are in line with results of the in vitro studies of $\mathbf{1} / \mathbf{1} \mathbf{a}$ activity against Candida albicans described in Chapter 2.5 . 
Table 6. Chosen results of docking studies of spiroboronates of AN2690, 1 and 1a with LeuRS of Candida albicans and Escherichia coli.

\begin{tabular}{|c|c|c|c|c|c|c|}
\hline & Ligand & $\begin{array}{c}\text { The Lowest } \\
\text { Binding Energy } \\
{[\mathrm{kcal} / \mathrm{mol}]}\end{array}$ & $\begin{array}{l}\text { Number of } \\
\text { Structures }\end{array}$ & $\begin{array}{c}\text { Mean Binding } \\
\text { Energy } \\
{[\mathrm{kcal} / \mathrm{mol}]}\end{array}$ & $\begin{array}{c}\text { Inhibition } \\
\text { Constant }\end{array}$ & $\begin{array}{l}\text { Number of } \\
\text { Hydrogen } \\
\text { Bonds }\end{array}$ \\
\hline \multirow{6}{*}{$\begin{array}{l}\text { Candida } \\
\text { albicans }\end{array}$} & AN2690-AMP & -11.98 & 17 & -10.80 & $1.93 \mathrm{nM}$ & 5 \\
\hline & 1a-R-AMP-A & -10.77 & 2 & -10.21 & $12.77 \mathrm{nM}$ & 4 \\
\hline & 1a-R-AMP-B & -11.83 & 3 & -11.66 & $2.12 \mathrm{nM}$ & 5 \\
\hline & 1a-S-AMP-A & -10.75 & 19 & -10.42 & $13.08 \mathrm{nM}$ & 3 \\
\hline & 1a-S-AMP-B & -11.59 & 4 & -10.94 & $3.17 \mathrm{nM}$ & 4 \\
\hline & 1-AMP & -11.05 & 2 & -10.77 & $7.95 \mathrm{nM}$ & 2 \\
\hline \multirow{6}{*}{$\begin{array}{l}\text { Escherichia } \\
\text { coli }\end{array}$} & AN2690-AMP & -8.27 & 22 & -7.55 & $865.19 \mathrm{nM}$ & 5 \\
\hline & 1a-R-AMP-A & -7.54 & 21 & -6.90 & $2.99 \mu \mathrm{M}$ & 2 \\
\hline & 1a-R-AMP-B & -8.15 & 2 & -7.81 & $1.09 \mu \mathrm{M}$ & 3 \\
\hline & 1a-S-AMP-A & -7.54 & 12 & -6.98 & $2.96 \mu \mathrm{M}$ & 2 \\
\hline & 1a-S-AMP-B & -7.72 & 4 & -7.45 & $2.21 \mu \mathrm{M}$ & 3 \\
\hline & 1-AMP & -8.23 & 4 & -7.75 & $924.99 \mathrm{nM}$ & 2 \\
\hline
\end{tabular}

In the cases of the studied bacteria, there is no published crystal structure of LeuRS bound to AN2690. Therefore, the E. coli LeuRS (4ARI) complex with ligand containing no fluorine atom (AN2679) was taken from the protein databank [30] and used in docking studies. In this case, the docking procedure covered only the binding domain of the enzyme. The ligands studied were the same as in the case of $C$. albicans (Table 6). Interestingly, the docking studies show that in the case of E. coli the opened isomer spiroboronate (1-AMP) displays the highest inhibition constant $(924.99 \mathrm{nM})$, comparable to that of AN2690-AMP, which is $865.19 \mathrm{nM}$. At the same time, all the closed isomers (1a) display inhibition constant at $\mu \mathrm{M}$ level (Table 6), which means that the opened isomer (1) should be more active in this case. It is worth to underline that the position of 1a-AMP as well as 1-AMP spiroboronates docked into the binding domain of E. coli LeuRS is different than that of the corresponding AN2690-AMP spiroboronate. It might suggest a different mechanism of action of $\mathbf{1}$ and $\mathbf{1 a}$ on bacterial strains. The structures docked into the enzyme have been presented at Figure 4.

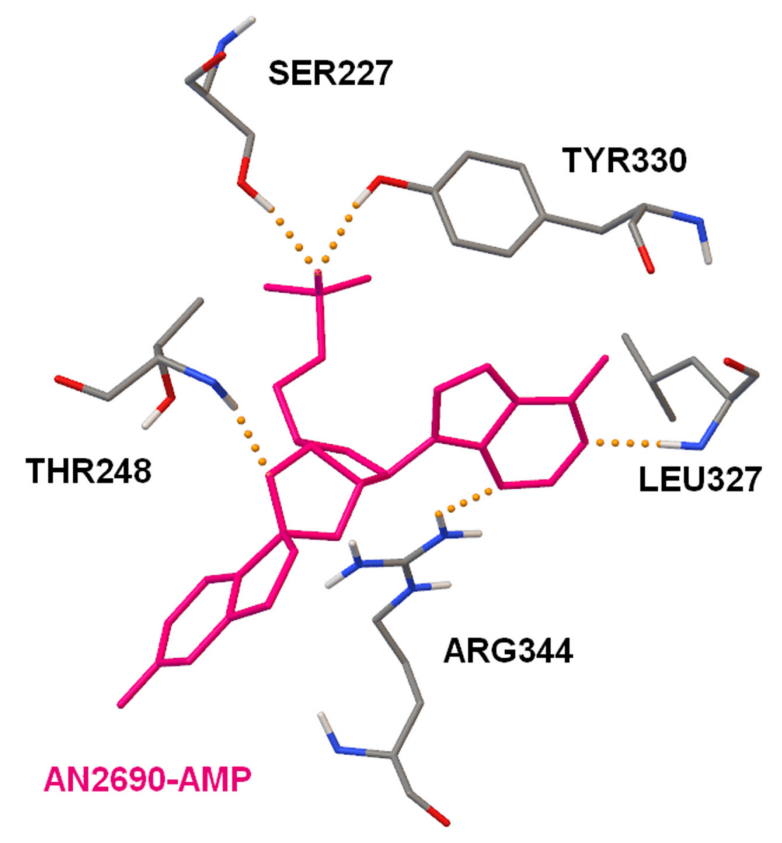

(A)

Figure 4. Cont. 


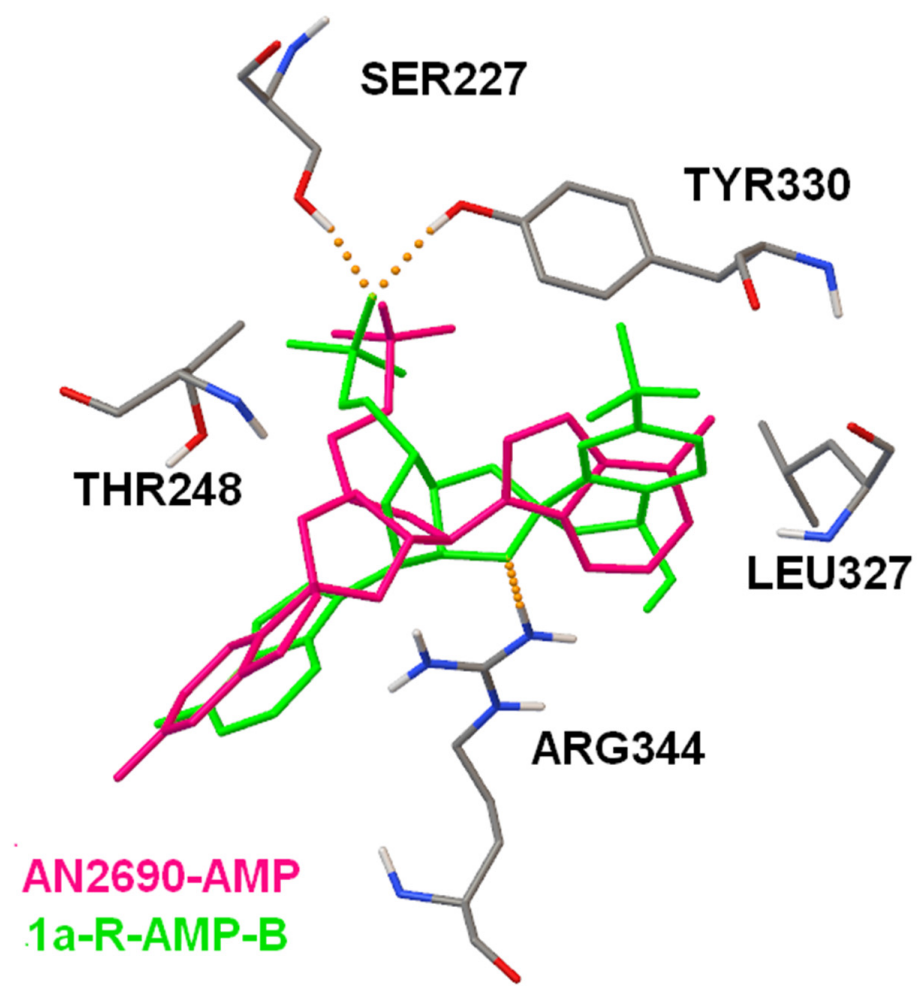

(B)

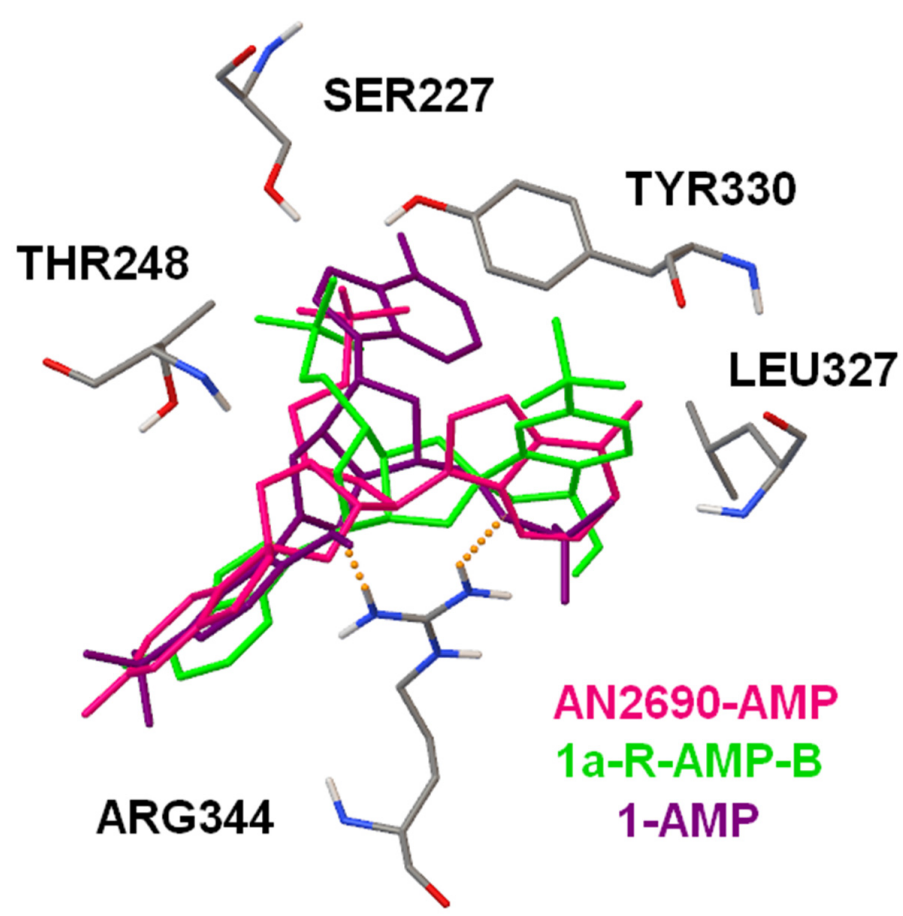

(C)

Figure 4. (A) The structure of AN2690-AMP spiroboronate docked into the E. coli LeuRS binding pocket (B) the AN2690-AMP spiroboronate (pink) along with 1a-AMP spiroboronate (green) (C) AN2690-AMP spiroboronate (pink) along with 1a-AMP spiroboronate (green) and 1-AMP spiroboronate (purple) docked into E. coli LeuRS. Dotted lines stand for hydrogen bonds. 


\subsection{In Vitro Studies of Antimicrobial Activity of $\mathbf{1}$}

Antimicrobial activity of $\mathbf{1}$ was established using both the agar diffusion method and by determination of minimal inhibitory concentration (MIC) values. DMSO has been used as a negative probe while the AN2690 and appropriate drugs have been treated as positive controls (Figure 5). The results of both methods are consistent, showing moderate antifungal as well antibacterial activity of 2-formyl-5-trifluoromethyl phenylboronic acid (1).

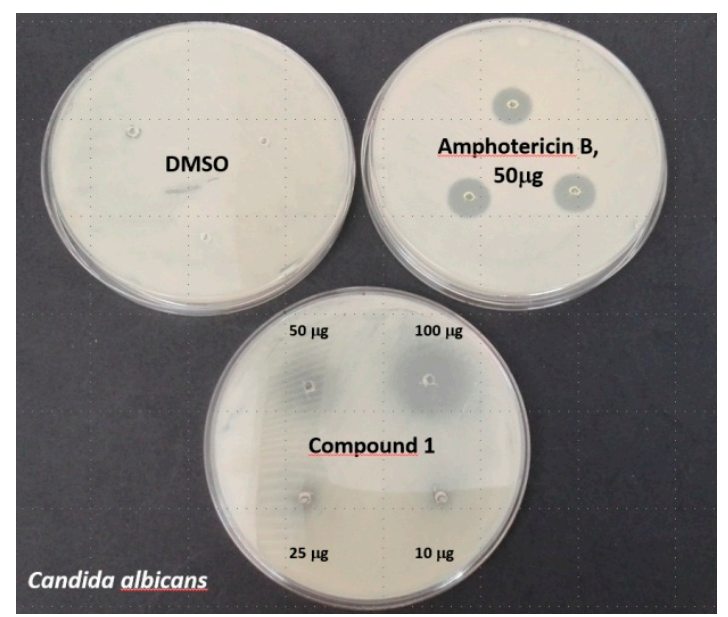

Figure 5. Results of agar diffusion method of activity against Candida albicans for a negative probe (DMSO), positive probe (50 $\mathrm{gg}$ of amphotericin B) and compound $\mathbf{1}$.

Gram (+) and Gram (-) bacterial strains were chosen as the representatives of two, different regarding the structure of the cell wall microbiota of various susceptibility towards the action of antibiotics. Whereas tested fungi were chosen because of their belonging to unicellular (C. albicans) and multicellular (A. niger) pathogenic fungi. In most of the studied cases, the title compound (1) limits the growth of the microorganisms. However, only at the highest dose studied $(100 \mu \mathrm{g})$ it totally inhibits the growth of Candida albicans and Aspergillus niger with a relatively small zone of inhibition of 8 and $5 \mathrm{~mm}$, respectively (Table 7).

Table 7. The diameter of the zone of inhibited growth of the microorganisms in millimeters.

\begin{tabular}{ccccccc}
\hline & $\mathbf{1 0} \boldsymbol{\mu g}$ & $\mathbf{2 5} \boldsymbol{\mu g}$ & $\mathbf{5 0} \boldsymbol{\mu g}$ & $\mathbf{1 0 0} \boldsymbol{\mu g}$ & AN2690 (50 $\boldsymbol{\mu g})$ & Antibiotic (50 $\boldsymbol{\mu g})$ \\
\hline Candida albicans & 0 & 9 & $13 \pm 2$ & $17 \pm 3(8 \pm 1)$ & $(53)$ & $(10 \pm 1)^{*}$ \\
Aspergillus niger & 0 & $8 \pm 1$ & $13 \pm 2$ & $26 \pm 4(5 \pm 1)$ & $(62)$ & $(9 \pm 1)^{*}$ \\
Escherichia coli & $2 \pm 1$ & $5 \pm 1$ & $7 \pm 1$ & $9 \pm 1$ & $(22)$ & $(16 \pm 1)^{\#}$ \\
Bacillus cereus & 12 & $15 \pm 1$ & 18 & $19 \pm 1$ & $(14)$ & $(21 \pm 1)^{\#}$ \\
\hline
\end{tabular}

* Amphotericin B, " Streptomycin. Values in parentheses () mean total inhibition of the growth of the microorganism.

The MIC values are also moderate, especially for Candida albicans $(250 \mu \mathrm{g} / \mathrm{mL}$, Table 8). The determined values of the diameter of the zone of inhibited growth of Candida albicans and Aspergillus niger show that they are several times higher for AN2690 than amphotericin B. It may result from a high diffusion of AN2690 within the applied media. Taking into account the MIC values, $\mathbf{1}$ is more active against Escherichia coli $(125 \mu \mathrm{g} / \mathrm{mL})$ and Aspergillus niger $(32 \mu \mathrm{g} / \mathrm{mL})$ than against Candida albicans $(250 \mu \mathrm{g} / \mathrm{mL})$. The reason for the lower activity of 1 towards tested fungi may be launched to low concentration of the presumably active isomer (1a-R) in water, which is the main component of the media applied for MIC determination. Docking studies show that in the case of E. coli, it is isomer $\mathbf{1}$ that displays three orders of magnitude higher inhibition constant than both AN2690 and isomer 1a. This is in line with a relatively high observed antibacterial activity of $\mathbf{1}$, which is a predominant form in aqueous solution. Needless to say that the issues of cell membrane permeability of the microorganism 
must be also taken into account. The lowest MIC value (highest activity) was determined for Bacillus cereus $(8 \mu \mathrm{g} / \mathrm{mL})$. It is significantly lower than that of the AN2690 $(62.5 \mu \mathrm{g} / \mathrm{mL})$ but still higher than that of the reference drug (streptomycin, $4 \mu \mathrm{g} / \mathrm{mL}$ ). The observed phenomenon may be addressed to a different structure of B. cereus membrane, as it is the representative of Gram positive bacteria, which are generally more sensitive for the action of antibiotics [31]. Worth noticing is a relatively high MIC value of AN2690 for Bacillus cereus, which is in line with previous findings on a rather low interactions of AN2690 with bacterial LeuRS [32].

Table 8. Minimal inhibitory concentrations (MIC) of 1, AN2690 and standard drugs (amphotericin and streptomycin).

\begin{tabular}{cccc}
\hline & \multicolumn{3}{c}{ MIC $[\mu \mathrm{g} / \mathrm{mL}]$} \\
\hline & $\mathbf{1}$ & AN 2690 & Antibiotic \\
\hline Candida albicans & 250 & 2 & $\leq 1{ }^{*}$ \\
Aspergillus niger & 32 & $\leq 1$ & - \\
Escherichia coli & 125 & 7.8 & $2^{\#}$ \\
Bacillus cereus & 8 & 62.5 & $4^{\#}$ \\
& $*$ Amphotericin B, ${ }^{\#}$ Streptomycin \\
\hline
\end{tabular}

\section{Materials and Methods}

\subsection{Synthesis and Isolation}

2-Bromo-4-trifluoromethylbenzaldehyde $(9.82 \mathrm{~g}, 38.7 \mathrm{mmol})$ was dissolved in $16 \mathrm{~mL}$ of methanol. Concentrated $\mathrm{H}_{2} \mathrm{SO}_{4}(0.2 \mathrm{~mL})$ was added and $5.33 \mathrm{~g}(50.3 \mathrm{mmol})$ of trimethyl orthoformate was added dropwise. The solution was refluxed for $1 \mathrm{~h}$ at $72{ }^{\circ} \mathrm{C}$ in an oil bath and left to cool down. Then the solution was brought to $\mathrm{pH} 11$ with a concentrated solution of $\mathrm{NaOMe}$ in methanol (NaOMe was synthetized by adding sodium metal into anhydrous methanol). After distillation of the volatiles at reduced pressure $\left(35-40{ }^{\circ} \mathrm{C}\right)$, the product was distilled under vacuum $\left(140-200{ }^{\circ} \mathrm{C}\right)$ to give $8.77 \mathrm{~g}$, $29.4 \mathrm{mmol}$ of 1-bromo-2-(dimethoxymethyl)-5-trifluoromethylbenzene as a colorless liquid (yield 75\%). ${ }^{1} \mathrm{H}$ NMR (300 MHz, Chloroform-d), 8/ppm: $7.83(\mathrm{~m}, 1 \mathrm{H}), 7.74(\mathrm{~m}, 1 \mathrm{H}), 7.60(\mathrm{~m}, 1 \mathrm{H}) 5.57(\mathrm{~s}, 1 \mathrm{H}), 3.39$ (s, $6 \mathrm{H}) ;{ }^{19} \mathrm{~F}$ NMR (282 MHz, Chloroform-d), $8 / \mathrm{ppm}$ : $-80.94 \mathrm{ppm}$ (s, 3F).

$62 \mathrm{~mL}$ of dry $\mathrm{Et}_{2} \mathrm{O}$ and $12 \mathrm{~mL}$ THF under argon flow were cooled down to $-75{ }^{\circ} \mathrm{C}$ using dry ice/acetone bath. $2.5 \mathrm{M} n$-butyllithium in hexanes $(12.0 \mathrm{~mL}, 31.43 \mathrm{mmol})$ was added. Next, 1-bromo-2-(dimethoxymethyl)-5-trifluoromethylbenzene $(8.71 \mathrm{~g}, 29.16 \mathrm{mmol})$ was added dropwise while keeping the temperature under $-70^{\circ} \mathrm{C}$. The colour of the mixture changed into green; the solution was stirred for $1 \mathrm{~h}$. Then $3.4 \mathrm{~g}(34.0 \mathrm{mmol})$ of triethyl borate was added slowly, keeping the temperature under $-70^{\circ} \mathrm{C}$; the colour of the mixture turned into greenish yellow; the solution was stirred for $1 \mathrm{~h}$. Cooling bath was removed and the solution was brought to $\mathrm{pH} 3$ with $3 \mathrm{M} \mathrm{aq} . \mathrm{HCl}$, while the temperature rose to $5{ }^{\circ} \mathrm{C}$. The aqueous layer was separated and extracted with $\mathrm{Et}_{2} \mathrm{O}(2 \times 50 \mathrm{~mL})$. The organic layers were combined and the solvent was partially removed under vacuum. After precipitation of a white solid $50 \mathrm{~mL}$ of water was added and distillation was continued to remove volatiles. The remaining solution was left for several hours in the refrigerator $\left(4^{\circ} \mathrm{C}\right)$, then two phases was observed: aqueous and oil. The aqueous phase was left for crystallization. After water evaporation, white crystals of pure title compound were received $(0.0563 \mathrm{~g})$. To the oil phase during stirring hexane was added resulting in separation of a solid. The white precipitate was filtered off. Pure product $\mathbf{1}$ was obtained from the filtrate by crystallization from an acetone:aqueous solution $(1.59 \mathrm{~g})$. The total amount obtained was $1.64 \mathrm{~g}$ ( $26 \%$ yield). The purity of product was confirmed on the basis of elemental analysis: calculated for: $\mathrm{C}_{8} \mathrm{H}_{6} \mathrm{BF}_{3} \mathrm{O}_{3} ; \mathrm{C}: 44.09, \mathrm{H}: 2.77$, found: $\mathrm{C}: 44.06 \pm 0.03, \mathrm{H}: 2.75 \pm 0.04 .{ }^{1} \mathrm{H}$ NMR (ppm): 10.04 (m, CHO), $8.54(\mathrm{~m}, 1 \mathrm{H}), 8.06(\mathrm{~m}, 1 \mathrm{H}), 7.97(\mathrm{~m}, 1 \mathrm{H}), 7.13(\mathrm{bs}, \mathrm{OH}) ;{ }^{11} \mathrm{~B}$ NMR $(\mathrm{ppm}): 27 ;{ }^{19} \mathrm{~F}$ NMR (ppm): 64.4. Spectra of $\mathbf{1}$ in various solvents are given in the text, Tables 3 and 5 as well as in the Supplementary Materials. 


\subsection{Single Crystal X-Ray Diffraction}

Single crystals of 1 suitable for $\mathrm{X}$-ray diffraction experiment were obtained by crystallization from water. Data were collected at room temperature on a Gemini A Ultra Diffractometer (Rigaku Oxford Diffraction, Wroclaw, Poland) with graphite monochromated Mo/Ka radiation $(\lambda=0.71073 \AA)$. Data collection and data reduction were performed in the CrysAlis ${ }^{\text {Pro }}$ program [33]. To solve and refine the structure, OLEX-2 version 1.2 [34] with incorporated SHELXT [35] and SHELXL (the full-matrix least-squares technique) programs [36,37] were used. All non-hydrogen atoms were refined with anisotropic temperature factors. The $\mathrm{OH}$-groups of hydrogen atoms were refined freely with fixed $\mathrm{O}-\mathrm{H}$ distance to $0.85(1) \AA$. The remaining $\mathrm{H}$-atoms were placed in calculated positions with fixed isotropic thermal parameters $\left(\mathrm{U}_{\text {iso }}(\mathrm{H})=1.2 \times\left[\mathrm{U}_{\text {eq }}(\mathrm{C})\right]\right)$. In both symmetrically independent molecules (1-I and 1-II) the $-\mathrm{CF}_{3}$ group showed rotational disorder. The final model with enhanced rigid body restrains (RIGU) and fixed C-F distances to 1.320(2) $\AA$ contains refined three distinct position of each group with the site occupation factor of 0.464(12), 0.352(14), 0.184(12) and 0.464(12), 0.359(14), 0.176(12) for 1-I and 1-II molecule, respectively. Molecular and packing diagrams were generated using ORTEP-3 for Windows (Oak Ridge National Lab, Oak Ridge, USA) [37] and OLEX-2 [34] programs, respectively. Crystal data for 1: $\mathrm{C}_{8} \mathrm{H}_{6} \mathrm{BF}_{3} \mathrm{O}_{3}(\mathrm{M}=217.94 \mathrm{~g} / \mathrm{mol})$ : triclinic, space group P-1 (no. 2), a = 7.6512(3) $\AA$, $\mathrm{b}=7.6813(4) \AA, \mathrm{c}=15.4975(6) \AA, \alpha=94.121(4)^{\circ}, \beta=98.795(3)^{\circ}, \gamma=91.504(4)^{\circ}, \mathrm{V}=897.13(7) \AA^{3}, \mathrm{Z}=$ $4, \mathrm{~T}=298 \mathrm{~K}, \mu(\mathrm{MoK} \alpha)=0.158 \mathrm{~mm}^{-1}, \mathrm{D}_{\text {calc }}=1.614 \mathrm{~g} / \mathrm{cm}^{3}, 19471$ reflections measured $\left(6.974^{\circ} \leq 20 \leq\right.$ $\left.65.7^{\circ}\right), 6111$ unique $\left(R_{\text {int }}=0.0308, R_{\text {sigma }}=0.0310\right)$, which were used in all calculations. The final $R_{1}$ was $0.0513(\mathrm{I}>2 \sigma(\mathrm{I}))$ and $\mathrm{wR} 2$ was 0.1586 (all data). CCDC (Cambridge Crystallographic Data Centre) 1959978 contains the supplementary crystallographic data for this paper. These data can be obtained free of charge from the CCDC, 12 Union Road, Cambridge CB2 1EZ, UK; Fax: +44 1223 336033; E-mail: deposit@ccdc.cam.ac.uk.

\subsection{Acidity Constant Determination}

The acidity constant was determined by spectrophotometric method according to the previously reported description $[22,25,26]$. The title compound was dissolved in aqueous phosphate buffer with $\mathrm{pH}=6.42$ and acidified to $\mathrm{pH}=2$ by hydrochloric acid. Next, the solution was titrated by $0.25 \mathrm{M}$ natrium hydroxide to $\mathrm{pH}=8 ; \mathrm{pH}$ value was measured by a standard combined glass electrode with temperature control, performed on the pH-meter (Hanna Edge, Woonsocked, RI, USA). Electrode was calibrated on the following buffer solutions: 4.01, 7.01, 9.18 and 10.01 (Hanna Instruments, Woonsocked, RI, USA). Spectrophotometric scan from $190 \mathrm{~nm}$ to $400 \mathrm{~nm}$ was done after each drop of titrant in $\mathrm{pH}$ range between 3.5 and 6.5, performed on the UV-3100 PC Spectrophotometer (VWR, Leuven, Belgium). Outside of the above-mentioned range, scans were done every change of the $0.5 \mathrm{pH}$ value. Further technical details are presented in Supplementary Materials.

\subsection{NMR Measurements}

All NMR experiments $\left({ }^{1} \mathrm{H},{ }^{11} \mathrm{~B},{ }^{13} \mathrm{C},{ }^{19} \mathrm{~F} N M R,{ }^{1} \mathrm{H}_{-}{ }^{1} \mathrm{H}\right.$ COSY and ${ }^{1} \mathrm{H}_{-}{ }^{13} \mathrm{C}$ HSQC $)$ were performed on Bruker Avance $300 \mathrm{MHz}$ (BioSpin, Poznan, Poland). For hydrogen and carbon spectrum residual signals from solvents were used as reference signals. For boron spectrum- $-\mathrm{BF}_{3} \cdot \mathrm{Et}_{2} \mathrm{O}$ and for fluorine spectrum $-\mathrm{CCl}_{3} \mathrm{~F}$ were used as external references.

\subsection{Docking Studies}

The structures of a leucyl-RS synthetase from Candida albicans as well as Escherichia coli have been taken from the Protein Databank [38]. The protein structure has been processed by AutoDock Tools [39] to remove water molecules, connect hydrogen atoms and calculate partial charges. The charges were calculated on the basis of standard force field parameters applied in AutoDock 4.2. Since the standard parameters in AutoDock do not cover boron atom, the following force-field parameters have been introduced: Rii (sum of vdW radii of two like atoms in $\AA$ ) $=1.98$; epsii $(\mathrm{vdW}$ well depth in $\mathrm{kcal} / \mathrm{mol})=$ 
0.034; vol (atomic solvation volume in $\AA^{3}$ ) $=4.6000$; solpar (atomic solvation parameter) $=-0.00110$; Rij_hb (H-bond radius of the heteroatom in contact with a hydrogen in $\AA$ ) = 0.0; epsij_hb (well depth of $\mathrm{H}$-bond in $\mathrm{kcal} / \mathrm{mol})=0$; $\mathrm{H}$-bond (integer indicating type of $\mathrm{H}$-bonding atom $(0=$ no $\mathrm{H}$-bond $)=0$; rec index (initialized to -1 , but later on holds count of how many of this atom type are in receptor) $=$ -1 ; bond index were used in AutoDock to detect bonds; see "mdist.h", enum $\{\mathrm{C}, \mathrm{N}, \mathrm{O}, \mathrm{H}, \mathrm{XX}, \mathrm{P}, \mathrm{S}\}=4$. The structures of investigated molecules $(\mathbf{1}, \mathbf{1 a})$ have been generated in Avogadro and optimized in Gaussian 03 (b3lyp, 6-311g (2d,p) opt freq.) (Gaussian Inc., Wallingford, CT, USA). In case of molecule $\mathbf{1}$, the position of the atoms has been taken from the crystal structure. The structures of spiroboronates with AMP were prepared by connection of optimized molecules with the AMP molecule taken from crystal structure of the AN2690-AMP spiroboronate found in the crystal phase [29]. The structures of such obtained spiroboronates were not optimized.

\subsection{Microbial Activity}

Our investigations addressed to microbial activity of 5-trifluoromethyl-2-formylphenylboronic acid, were performed towards four representatives belonging to different taxa of microorganisms: filamentous fungi-Aspergillus niger LOCK 0440, yeast-Candida albicans LOCK 001, Gram-positive bacteria-Bacillus cereus CCM 2010 and Gram-negative bacteria-Escherichia coli CCM 5172. Fungal species used for those experiments were obtained from the Institute of Fermentation Technology and Microbiology (University of Technology, Łódź, Poland), whereas examined bacteria were purchased from Czech Collection of Microorganisms (Masaryk University, Prague, Czech Republic). Before the examinations, A. niger was routinely cultured in potato dextrose agar at $27^{\circ} \mathrm{C}, \mathrm{C}$. albicans in yeast extract-peptone-dextrose (YPD) medium at $27^{\circ} \mathrm{C}$ while bacteria were pre-grown in nutrient broth at $34^{\circ} \mathrm{C}$.

Antimicrobial activity of tested compound was established using both the agar-diffusion method and by determining MIC values. For the diffusion tests, $0.5 \mathrm{~mL}$ of appropriate inoculum containing $10^{6}-10^{7}$ spores or bacterial cells was placed on the surface of the solidified media suitable for the growth of fungi or bacteria respectively and allowed to dry. The A. niger spore suspension was prepared by washing the surface of the 10- to 14-day-old cultures with $0.05 \%$ Tween solution and quantified using the Thom's chamber. In case of the rest of microorganisms the 24-h old cultures, diluted in a proper medium if necessary, were used. In such prepared cultures, 2-mm wells were cut and filled with $15 \mu \mathrm{L}$ DMSO containing 100, 50, 25 or $10 \mu \mathrm{g}$ of the tested compound. As the controls DMSO, $50 \mu \mathrm{g}$ of AN2690 and solutions of $50 \mu \mathrm{g}$ of the appropriate antibiotic were used. Cultures of Aspergillus niger and Candida albicans were incubated for $48 \mathrm{~h}$, while the cultures of other examined strains for $24 \mathrm{~h}$. Experiments were carried out at least in triplicate. Antimicrobial activity was evaluated based on the comparison of the diameter of the zone of inhibition of microbial growth around the wells, measured both in controls and experimental treatments.

The Minimal Inhibitory Concentration (MIC) was determined by a serial dilution method. For this purpose, $2 \mathrm{~mL}$ of microbial cultures containing $10^{6} \mathrm{CFU}$ per $1 \mathrm{~mL}$ of medium were prepared. Media used in MIC evaluation were Czapek Medium for A. niger, YPD medium for C. albicans and nutrient broth for E. coli and B. cereus. Stock solutions of 1 and AN2690 were prepared by dissolving in DMSO. To obtain the set of experimental concentrations, the stock solution was serially diluted and placed to cultures, ensuring that the final concentration ranged from 1 to $500.0 \mu \mathrm{g} / \mathrm{mL}$. Depending on the species of microorganism, appropriate cultures were incubated for $72 \mathrm{~h}$ (A. niger), $48 \mathrm{~h}$ (C. albicans) at $25^{\circ} \mathrm{C}$ or $24 \mathrm{~h}$ at $34^{\circ} \mathrm{C}$ (E. coli, B. cereus). The experiments were performed in triplicate. The MIC values were determined based on the lowest concentration of tested compound required to visual inhibition of fungal or bacterial growth.

\section{Conclusions}

The 2-formylphenylboronic acid containing the trifluoromethyl substituent at meta position (1) has been synthesized and characterized in terms of its structure and properties. The molecule displays typical dimeric structural motive in the solid state and a relatively high acidity. In DMSO, acetone and 
aqueous solutions $\mathbf{1}$ isomerizes with the formation of a cyclic isomer (1a) resembling the benzoxaborole structure. Antimicrobial activity of $\mathbf{1}$ and AN2690 against Candida albicans, Aspergillus niger as well as Escherichia coli and Bacillus cereus has been evaluated. Docking studies of an antifungal benzoxaborole drug AN2690 (Tavaborole, Kerydin), 1 and 1a showed possible binding of the cyclic isomer 1a into the binding pocket of Candida albicans' cytoplasmic LeuRS. On the contrary, in case of the bacterial LeuRS (E. coli), isomer 1 displays higher inhibition constant than both 1a and AN2690. The antimicrobial activity of the title compound investigated in vitro is in line with those findings, showing moderate action against Candida albicans, which may result from relatively low amount of $\mathbf{1 a}$ in aqueous media. The title compound reveals higher activity against bacteria such as Escherichia coli and Bacillus cereus. In case of the latter, the determined MIC value is lower than that of AN2690. The considerable antibacterial activity of $\mathbf{1}$ can result from both its interactions with bacterial LeuRS (higher inhibition constant in comparison with AN2690 and 1a) as well as high concentration of $\mathbf{1}$ isomer in aqueous media. The results confirm a potential of 2-formylphenylboronic acids as antibacterial agents and give a hint of their possible mechanism of action.

Supplementary Materials: The following are available online at http://www.mdpi.com/1420-3049/25/4/799/s1: Figures S1-24: NMR spectra of 1 in various solvents, S25-44: Input and optimal structures in docking studies. Figures S45-52: Examples of results of agar diffusion method. Tables S1 and S2: Bond lengths and selected bond angles in molecules of 1 -data from X-ray studies. Table S3: Values of acidity constant determined in triplicate. Tables S4-23: Coordinates of the input and optimal structures in docking studies.

Author Contributions: Conceptualization: A.A.-W., D.W., J.L. and E.K.; investigation: J.T.G., D.W., E.K.; I.D.M. writing-original draft preparation: A.A.-W., J.T.G., D.W.; writing-review and editing: A.A.-W., A.S., J.L., visualization: J.T.G., D.W., E.K., A.A.-W.; supervision: A.A.-W.; project administration: A.A.-W., J.L.; funding acquisition: A.A.-W., J.L.; synthesis: E.B., J.T.G.; measuring NMR spectra, $\mathrm{p} K_{\mathrm{a}}$ determination: J.T.G.; docking studies: E.K.; antimicrobial activity studies: D.W.; crystal structure determination and discussion: I.D.M. All authors have read and agreed to the published version of the manuscript.

Funding: This research was funded by National Science Centre, Poland, grant number 2016/23/B/ST5/02847.

Conflicts of Interest: The authors declare no conflicts of interest.

\section{References}

1. Gozdalik, J.T.; Adamczyk-Woźniak, A.; Sporzyński, A. Influence of fluorine substituents on the properties of phenylboronic compounds. Pure Appl. Chem. 2018, 90, 677-702. [CrossRef]

2. Boron: Sensing, Synthesis and Supramolecular Self-Assembly. Meng, L.; Fossey, J.S.; James, T.D. (Eds.) Monographs in Supramolecular Chemistry; Royal Society of Chemistry: Cambridge, UK, 2015; ISBN 978-1-84973-674-9.

3. Boronic Acids. Preparation and Applications in Organic Synthesis, Medicine and Materials, 2nd ed.; Hall, D.G., Ed.; WILEY-VCH: Weinheim, Germany, 2011.

4. Cheng, T.; Li, H.; Ma, Y.; Liu, X.; Zhang, H. Synthesis of boronic-acid-functionalized magnetic attapulgite for selective enrichment of nucleosides. Anal. Bioanal. Chem. 2015, 407, 3525-3529. [CrossRef] [PubMed]

5. Evangelista, L.; Jori, G.; Martini, D.; Sotti, G. Boron neutron capture therapy and 18F-labelled borophenylalanine positron emission tomography: A critical and clinical overview of theliterature. Appl. Radiat. Isot. 2013, 74, 91-101. [CrossRef] [PubMed]

6. Adamczyk-Woźniak, A.; Borys, K.M.; Sporzyński, A. Recent Developments in the Chemistry and Biological Applications of Benzoxaboroles. Chem. Rev. 2015, 115, 5224-5247. [CrossRef] [PubMed]

7. Madura, I.D.; Adamczyk-Woźniak, A.; Sporzyński, A. Diversified self-association through O-H...O hydrogen bonds in crystals of formylphenylboronic acid isomers. J. Mol. Struct. 2015, 1083, 204-211. [CrossRef]

8. Luliński, S.; Madura, I.; Serwatowski, J.; Szatyłowicz, H.; Zachara, J. A tautomeric equilibrium between functionalized 2-formylphenylboronic acids and corresponding 1,3-dihydro-1,3-dihydroxybenzo[c][2,1]oxaboroles. New J. Chem. 2007, 31, 144-154. [CrossRef]

9. Borys, K.M.; Wieczorek, D.; Pecura, K.; Lipok, J.; Adamczyk-Woźniak, A. Antifungal activity and tautomeric cyclization equilibria of formylphenylboronic acids. Bioorg. Chem. 2019, 91, 103081. [CrossRef] 
10. Kowalska, K.; Adamczyk-Woźniak, A.; Gajowiec, P.; Gierczyk, B.; Kaczorowska, E.; Popenda, Ł.; Schroeder, G.; Sikorski, A.; Sporzyński, A. Fluoro-substituted 2-formylphenylboronic acids: Structures, properties and tautomeric equilibria. J. Fluor. Chem. 2016, 187, 1-8. [CrossRef]

11. Das, S.; Alexeev, V.L.; Sharma, A.C.; Geib, S.J.; Asher, S.A. Synthesis and crystal structure of 4-amino-3-fluorophenylboronic acid. Tetrahedron Lett. 2003, 44, 7719-7722. [CrossRef]

12. Alexeev, V.L.; Sharma, A.C.; Goponenko, A.V.; Das, S.; Lednev, I.K.; Wilcox, C.S.; Finegold, D.N.; Asher, S.A. High ionic strength glucose-sensing photonic crystal. Anal. Chem. 2003, 75, 2316-2323. [CrossRef]

13. Kirsch, P. Modern Fluoroorganic Chemistry: Synthesis, Reactivity, Applications, 2nd ed.; WILEY-VCH: Darmstadt, Germany, 2013; ISBN 9783527603930.

14. Purser, S.; Moore, P.R.; Swallow, S.; Gouverneur, V. Fluorine in medicinal chemistry. Chem. Soc. Rev. 2008, 37, 320-330. [CrossRef] [PubMed]

15. Liu, F.; Tian, J.; Liu, Y.; Tao, C.; Zhu, H.; Zhang, A.; Xua, D.; Zhao, B. Decarboxylative Umpolung of conjugated enals to $\beta$-carbanions for intramolecular nucleophilic addition to an aldehyde. Org. Chem. Front. 2017, 4, 1586-1589. [CrossRef]

16. Etter, M.C.; MacDonald, J.C.; Bernstein, J. Graph-set analysis of hydrogen-bond patterns in organic crystals. Acta Crystallogr. Sect. B Struct. Sci. 1990, 46, 256-262. [CrossRef]

17. McKinnon, J.J.; Spackman, M.A.; Mitchell, A.S. Novel tools for visualizing and exploring intermolecular interactions in molecular crystals. Acta Crystallogr. Sect. B Struct. Sci. 2004, 60, 627-668. [CrossRef]

18. Yan, J.; Springsteen, G.; Deeter, S.; Wang, B. The relationship among $\mathrm{p} K_{\mathrm{a}}, \mathrm{pH}$, and binding constants in the interactions between boronic acids and diols-It is not as simple as it appears. Tetrahedron 2004, 60, 11205-11209. [CrossRef]

19. Yamamoto, Y.; Matsumura, T.; Takao, N.; Yamagishi, H.; Takahashi, M.; Iwatsuki, S.; Ishihara, K. Fast trigonal/tetragonal interconversion followed by slow chelate-ring closure in the complexation of boronic acids. Inorg. Chim. Acta 2005, 358, 3355-3361. [CrossRef]

20. Westmark, P.R.; Gardiner, S.J.; Smith, B.D. Selective monosaccharide transport through lipid bilayers using boronic acid carriers. J. Am. Chem. Soc. 1996, 118, 11093-11100. [CrossRef]

21. Siodła, T.; Ozimiński, W.P.; Hoffmann, M.; Koroniak, H.; Krygowski, T.M. Toward a physical interpretation of substituent effects: The case of fluorine and trifluoromethyl groups. J. Org. Chem. 2014, 79, 7321-7331. [CrossRef]

22. Zarzeczańska, D.; Adamczyk-Woźniak, A.; Kulpa, A.; Ossowski, T.; Sporzyński, A. Fluorinated Boronic Acids: Acidity and Hydrolytic Stability of Fluorinated Phenylboronic Acids. Eur. J. Inorg. Chem. 2017, 2017, 4493-4498. [CrossRef]

23. Gozdalik, J.T.; Marek, P.H.; Madura, I.D.; Gierczyk, B.; Popenda, Ł.; Schroeder, G.; Adamczyk-Woźniak, A.; Sporzyński, A. Structures and properties of trifluoromethylphenylboronic acids. J. Mol. Struct. 2019, 1180, 237-243. [CrossRef]

24. Torssell, K.; McClendon, J.H. Chemistry of Arylboric Acids VIII. The Relationship between Physico-chemical Properties and Activity in Plants. Acta Chem. Scand. 1958, 12, 1373-1385. [CrossRef]

25. Tomsho, J.W.; Pal, A.; Hall, D.G.; Benkovic, S.J. Ring Structure and Aromatic Substituent Effects on the $\mathrm{p} K_{\mathrm{a}}$ of the Benzoxaborole Pharmacophore. ACS Med. Chem. Lett. 2011, 3, 48-52. [CrossRef] [PubMed]

26. Adamczyk-Woźniak, A.; Cabaj, M.K.; Dominiak, P.M.; Gajowiec, P.; Gierczyk, B.; Lipok, J.; Popenda, Ł.; Schroeder, G.; Tomecka, E.; Urbański, P.; et al. The influence of fluorine position on the properties of fluorobenzoxaboroles. Bioorg. Chem. 2015, 60, 130-135. [CrossRef] [PubMed]

27. Adamczyk-Woźniak, A.; Ejsmont, K.; Gierczyk, B.; Kaczorowska, E.; Matuszewska, A.; Schroeder, G.; Sporzyński, A.; Zarychta, B. Novel 2,6-disubstituted phenylboronic compounds: Synthesis, crystal structures, solution behaviour and reactivity. J. Organomet. Chem. 2015, 788, 36-41. [CrossRef]

28. Dolbier, W.R., Jr. Guide to Fluorine NMR for Organic Chemists, 2nd ed.; Wiley: Hoboken, NJ, USA, 2016.

29. Rock, F.L.; Mao, W.; Yaremchuk, A.; Tukalo, M.; Crepin, T.; Zhou, H.; Zhang, Y.-K.; Hernandez, V.; Akama, T.; Baker, S.J.; et al. An Antifungal Agent Inhibits an Aminoacyl-tRNA Synthetase by Trapping tRNA in the Editing Site. Science 2007, 316, 1759-1761. [CrossRef]

30. Palencia, A.; Crepin, T.; Vu, M.T.; Lincecum, T.L., Jr.; Martinis, S.A.; Cusack, S. Structural Dynamics of the Aminoacylation and Proofreading Functional Cycle of Bacterial Leucyl-tRNA Synthetase. Nat. Struct. Mol. Biol. 2012, 19, 677. [CrossRef] 
31. Gualerzi, C.O.; Brandi, L.; Fabbretti, A.; Pon, C.L. Antibiotics: Targets, Mechanism and Resistance; Wiley: Hoboken, NJ, USA, 2013.

32. Kim, S. (Ed.) Aminoacyl-tRNA Synthetases in Biology and Medicine. In Topics in Current Chemistry; Springer Verlag: Berlin Heidelberg, Germany, 2014; p. 312.

33. CrysAlisPro 1.171.38.46, Rigaku; Oxford Diffraction: Abingdon-on-Thames, UK, 2015.

34. Dolomanov, O.V.; Bourhis, L.J.; Gildea, R.J.; Howard, J.A.K.; Puschmann, H. OLEX2: a complete structure solution, refinement and analysis program. J. Appl. Crystallogr. 2009, 42, 339-341. [CrossRef]

35. Sheldrick, G.M. SHELXT-Integrated space-group and crystal-structure determination. Acta Crystallogr. Sect. A Found. Adv. 2015, 71, 3-8. [CrossRef]

36. Sheldrick, G.M. Crystal structure refinement with SHELXL. Acta Crystallogr. Sect. C Struct. Chem. 2015, 71, 3-8. [CrossRef]

37. Farrugia, L.J. Ortep-3 for Windows-a version of ORTEP-III with a Graphical User Interface (GUI). J. Appl. Crystallogr. 1997, 30, 565. [CrossRef]

38. Burley, S.K.; Berman, H.M.; Bhikadiya, Ch.; Bi, Ch.; Chen, L.; Di Costanzo, L.; Christie, C.; Dalenberg, K.; Duarte, J.M.; Dutta, S.; et al. RCSB Protein Data Bank: biological macromolecular structures enabling research and education in fundamental biology, biomedicine, biotechnology and energy. Nucleic Acids Res. 2019, 47, D464-D474. Available online: www.rcsb.org (accessed on 11 December 2019). [CrossRef] [PubMed]

39. Morris, G.M.; Huey, R.; Lindstrom, W.; Sanner, M.F.; Belew, R.K.; Goodsell, D.S.; Olson, A.J. Autodock4 and AutoDockTools4: automated docking with selective receptor flexiblity. J. Comput. Chem. 2009, 16, 2785-2791. Available online: http://autodock.scripps.edu/ (accessed on 11 December 2019). [CrossRef] [PubMed]

(C) 2020 by the authors. Licensee MDPI, Basel, Switzerland. This article is an open access article distributed under the terms and conditions of the Creative Commons Attribution (CC BY) license (http://creativecommons.org/licenses/by/4.0/). 